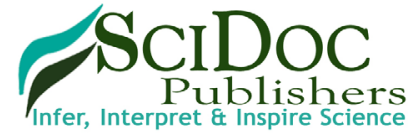

\author{
International Journal of Surgery and Research (IJSR)
}

ISSN : 2379-156X

\title{
Negative Pressure Therapy with Intraperitoneal Saline Instillation in the Open Septic Abdomen
}

Short Communication

\author{
Jiménez-Fuertes $\mathrm{M}^{1 *}$, Ruiz-Tovar $\mathrm{J}^{1}$, Durán-Poveda $\mathrm{M}^{1}$, Garcia-Olmo $\mathrm{D}^{2}$ \\ ${ }^{1}$ Department of Surgery, Rey Juan Carlos University Hospital, Móstoles (Madrid), Spain. \\ ${ }^{2}$ Department of Surgery, Fundción Jiménez-Díaz University Hospital, Madrid, Spain.
}

\section{Abstract}

Introduction: Open abdomen has become a common technique in the management of abdominal sepsis. We present a series of cases of 12 open septic abdomen treated by using intermittent therapy with intra-abdominal irrigation with a modified VAC- Ulta ${ }^{\circledR}$ associated with ABThera ${ }^{\circledR}$ dressing, comparing with ABThera ${ }^{\circledR}$ dressing suction therapy alone.

Methods: Pilot prospective study of 12 consecutive patients with temporary abdominal closure for abdominal sepsis. During the initial laparotomy washing of the peritoneal cavity was performed with warm saline. Six patients (Goup 1) were treated by KCI ABThera ${ }^{\circledR}$ dressing, and keeping constant suction pressure $-125 \mathrm{mmHg}$. For the second group (Group 2) the mentioned dressing was used, and we performed also intermittent intra-abdominal instillation with modified VAC-Ulta ${ }^{\circledR}$. Results: Primary fascial closure was achieved in $100 \%$ of patients with instillation therapy, 4 of them in the first change after 3 days, and the other 2 patients in the second change ( $6^{\text {th }}$ day). In the group 1 , only 3 of them were closed (at $3^{\text {th }}, 6^{\text {th }}$ and $11^{\text {th }}$ day). Two of them remained with the open abdomen and the other one died. In patients with instillation therapy, there were no intra-abdominal complications after closure.

Conclusions: The results obtained by combining the intra-abdominal instillation therapy with suction seem to be promising, regarding the rate of abdominal closure, reducing the time to primary fascial closure and consequently in fewer complications associated with open abdomen.

Keywords: Vac-Instill; Open Abdomen; Abdominal Sepsis; Negative Pressure Therapy.

Abbreviations: CAT: Temporary Abdominal Closure; ACS: Abdominal Compartment Syndrome; DCS: Damage Control Surgery; ARSD: Adult Respiratory Distress Syndrome; MODS: Multiple Organ Dysfunction Syndrome.

\section{Introduction}

Temporary Abdominal Closure (CAT) is one of the fundamental tools for the current treatment of Abdominal Compartment Syndrome (ACS) for damage control surgery (DCS) and for severe abdominal sepsis. Techniques for maintaining open abdomen have evolved over time, although it is now accepted that therapies with negative pressure are superior to other therapies in regard to abdominal sepsis by removing peritoneal fluid rich in proinflammatory mediators, and the best results are seen with pressures of $-125 \mathrm{mmHg}[1-3]$.

In peritonitis, sepsis occurs when an intra-abdominal focus of in- fection triggers an inflammatory response. This response is characterized by activation of several physiological systems (complement, coagulation, fibrinolysis) and cell populations, (endothelial cells, leukocytes, monocytes, macrophages and mast cells) and the release of chemical mediators (oxygen free radicals, histamine, eicosanoids, clotting factors and cytokines). The local inflammatory response that occurs during sepsis associated to the intestine is a risk factor for the development of Adult Respiratory Distress Syndrome (ARSD) as intestinal microcirculation is seriously damaged during septic shock and hemorrhagic shock [4]. This impairment of microcirculation causes tissue hypoxia and alterations in endothelial and epithelial function [5], an increase in microvascular permeability that determines the appearance of intestinal

\footnotetext{
*Corresponding Author

Montiel Jiménez-Fuertes,

Department of Surgery, Rey Juan Carlos University Hospital, Móstes (Madrid), Spain.

Tel: +34629966013

E-mail: montiel.jf77@gmail.com
}

Received: November 30, 2016

Accepted: December 07, 2016

Published: December 12, 2016

Citation: Jiménez-Fuertes M, Ruiz-Tovar J, Durán-Poveda M, Garcia-Olmo D (2016) Negative Pressure Therapy with Intraperitoneal Saline Instillation in the Open Septic Abdomen. Int J Surg Res, S3:001, 1-4. doi: http://dx.doi.org/10.19070/2379-156X-SI03001

Copyright: Jiménez-Fuertes $\mathbf{M}^{\mathcal{O}}$ 2016. This is an open-access article distributed under the terms of the Creative Commons Attribution License, which permits unrestricted use, distribution and reproduction in any medium, provided the original author and source are credited. 
edema and ascites formation, making the damaged intestine an area of inflammation sworn to ARDS and damage to other organs distance $[6,7]$.

Kubiak et al., showed that the Multiple Organ Dysfunction Syndrome (MODS) comes from an alteration of the inflammatory cascade system where the source is a vicious circle with abdominal start (activation and release of physiological, cellular systems and chemical mediators triggered) that stars inflammation-damageinflammation, abdominal level first and then systemically [8].

In the other side, with the use of vac therapy associated with instillation (VAC-Ulta, $\mathrm{KCI}^{\circledR}$, San Antonio, Texas) it seems that the combination of the negative pressure together with the topical instillation has shown significant reduction in the time of wound closure compared with the aspiration alone, and even, Tao and D'Hondt have reported promising results with abdominal surface irrigation $[9,10]$.

Moreover, as published Nunes et al., [11], the peritoneal washing with saline solution has a beneficial effect on the systemic inflammatory response in the context of peritonitis.

We present a series of cases of septic open abdomen with use of intermittent therapy with intra-abdominal irrigation Ulta ${ }^{\circledR}$ KCI VAC-modified system associated with ABThera dressing (KCI, San Antonio, Texas), comparing with vacuum therapy with ABThera dressing only in a similar group of patients.

\section{Materials and Methods}

\section{Technique}

This is a retrospective study of 12 patients with temporal abdominal closure for abdominal sepsis (peritonitis secondary to perforated hollow viscera) between January 2013 and January 2015.

In all cases preoperative resuscitation was performed with intravenous fluids, analgesia, antibiotics and decompression by nasogastric tube. The site of the origin of the peritonitis was diagnosed and treated in all cases during surgery.

During the initial laparotomy washing out of the peritoneal cavity was performed with warm saline at $38^{\circ} \mathrm{C}$. After that, the first six patients (group 1 comprised between 2013 and 2014) were treated by KCI AbThera ${ }^{\circledR}$ dressing for open abdomen, maintaining a constant suction pressure of $-125 \mathrm{mmHg}$ (Figure 1). For the second group of patients (group 2: those treated between 2014 and 2015) also mentioned the dressing was introduced into the abdominal cavity and performing the intermittent instillation with VAC-Ul$\mathrm{ta}^{\circledR}$ (the irrigation catheter, previously multiperforated with scissors, was placed deep within the abdominal cavity, distributing circular in gutters, to subdiaphragmatic and pelvic level, as shown in Scheme 1). By programming the device, intermittent flushing was performed every hour with $250 \mathrm{ml}$ of saline heated to $38^{\circ}$ $\mathrm{C}$ inside the abdominal cavity acting for 5 minutes, after which the suction to $-125 \mathrm{mmHg}$ until the next hour, and the irrigation restarted again, performing this action until the definitive closure of the abdomen (Figures 2 and 3).

All patients included in the analysis were over 18 years old, and all of them had a peritonitis with score equal to or greater than 26 Mannheim Peritonitis Index (12), and no previous abdominal wall defects before the first surgery. Definitive abdominal closure was considered primary when it could reach full fascial closure during the initial hospital stay.

The patient characteristics are shown in Table 1. Of the twelve consecutive patients, 4 were males and 8 were females.

\section{Results}

Four of the six patients treated with instillation and aspiration group (group 2) were closed during the first change after 72 hours of the first surgery, finding the abdomen macroscopically clean at the discretion of the surgeon who performed the operation, while only one patient of the suction therapy (group 1) it was closed in the first change after 72 hours (Table 1).

The primary fascial closure was achieved in the $100 \%$ of patients with instillation therapy, 4 of them in the first change after 3 days, and the other 2 patients in the second shift at 6 days. In the group 1 , the definitive closure was achieved only in 3 of them, after 3 days, 6 days and 11 days after the first operation. Two of them remained with the open abdomen and topical therapy aspiration and one of them died after 19 days after the first surgery without closure.

As for complications, one patient with suction therapy presented an intestinal fistula, and two of them had intra-abominal abscesses who were treated percutaneously.

In patients with instillation therapy, there were no intra-abdominal complications after closure.

Figure 1. Group 1: AbThera ${ }^{\circledR}$ Dressing for Open Abdomen, Maintaining a Constant Suction Pressure of $-125 \mathrm{mmHg}$.

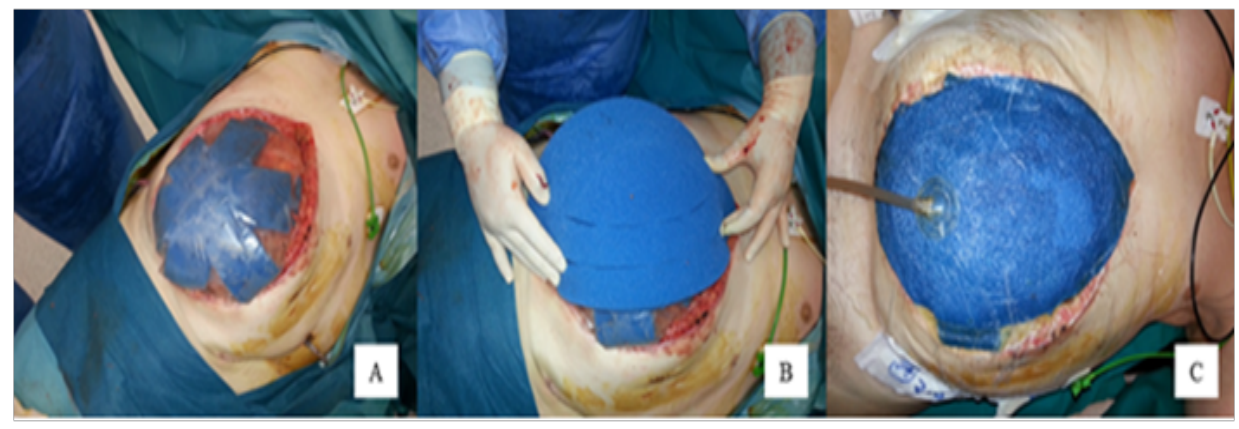


Figure 2. Group 2: The irrigation catheter, previously multiperforated with scissors, was placed deep within the abdominal cavity, distributing circular in gutters, to subdiaphragmatic and pelvic level, as shown in Scheme 1). AbThera ${ }^{\circledR}$ dressing for open abdomen was placed after that in the normal way covering the surface of the bowels.

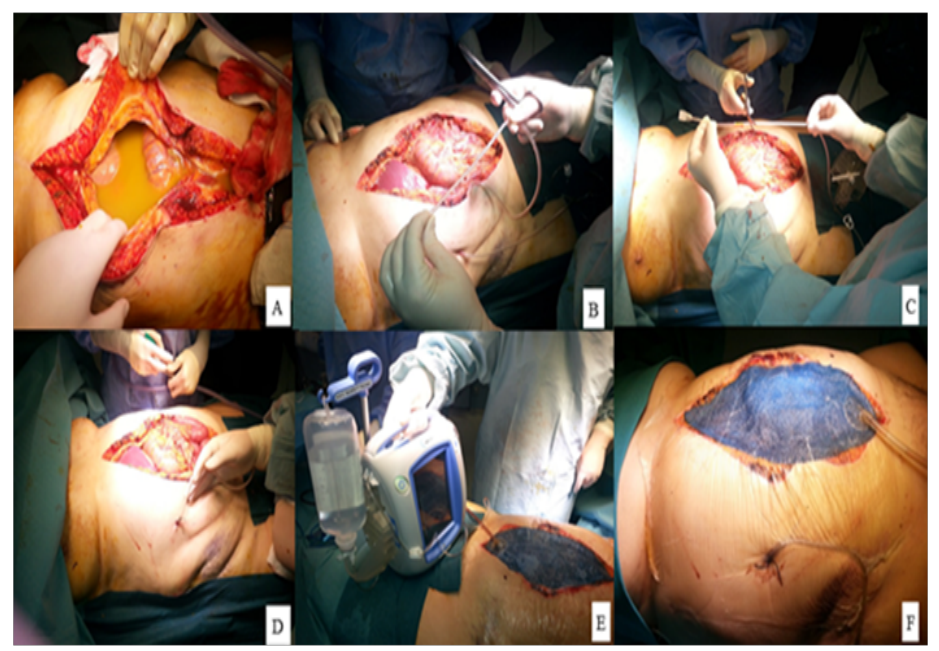

Figure 3. Group 2: By programming the device, intermittent flushing was performed every hour with $250 \mathrm{ml}$ of saline heated to $38^{\circ} \mathrm{C}$ inside the abdominal cavity acting for 5 minutes, and after the suction restarted again.

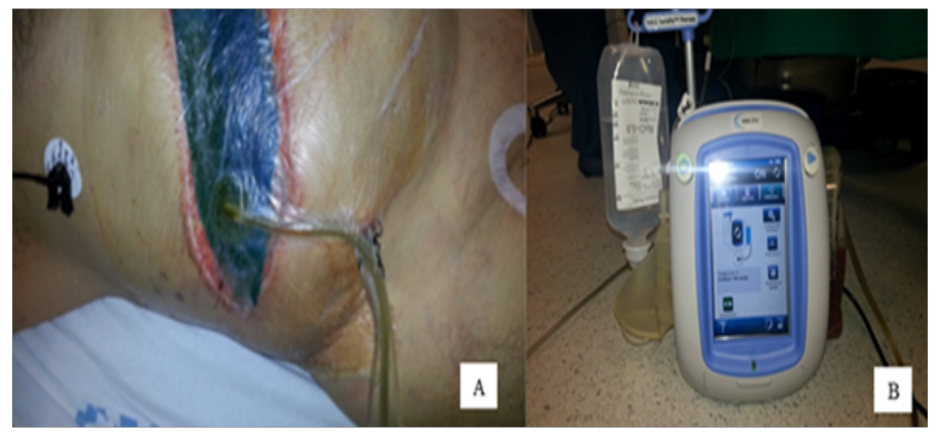

Scheme. The irrigation catheter, previously multiperforated with scissors, was placed deep within the abdominal cavity, distributing circular in gutters, to subdiaphragmatic and pelvic level. AbThera ${ }^{\circledR}$ dressing is placed as the usual way, covering the surface of the bowels.

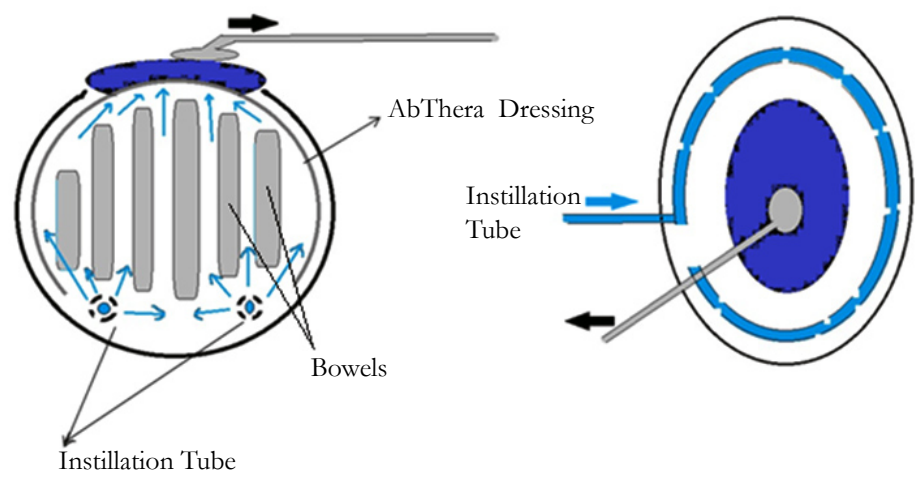

The average of hospital stay in the group with instillation was 16 days, and it was 33 days for the group without instillation.

\section{Discussion}

Negative aspiration therapy has been widely used for the treatment of complex wounds. The benefits of this therapy have been documented are improved tissue perfusion, promoting granulation tissue and reduction of edema, and bacterial clearance [13]. The combination of this aspiration therapy with instillation has shown very good results in the treatment of wounds, and also in the open abdomen treatment for infection control surface in this context [10].

Though this is not a prospective randomized study, the results obtained by combining the intra-abdominal instillation therapy and aspiration with AbThera dressing seem to be promising in terms of the improvement in the rate of abdominal closure, reducing the time to get closing and therefore reducing the number of complications associated with prolonged open abdomen, although it should be noted that this is a small number of patients 
Table 1. Patient Characteristics.

\begin{tabular}{|c|c|c|}
\hline & $\begin{array}{c}\text { Group 1 } \\
\text { (suction therapy group) }\end{array}$ & $\begin{array}{c}\text { Group 2 ( suction + } \\
\text { instillation therapy group) }\end{array}$ \\
\hline Number of patients & 6 & 6 \\
\hline Hospital stay & 33 days & 16 days \\
\hline $\begin{array}{c}\text { Number of patients with primary fascial closure } \\
\text { Average time for primary fascial closure (only those } \\
\text { with primary closure) }\end{array}$ & 3 patients $(50 \%)$ & 6 patients $(100 \%)$ \\
\hline $\begin{array}{c}\text { Abdominal complications } \\
677 \text { days }\end{array}$ & 4 days \\
\hline Death & $\begin{array}{c}\text { Intestinal fistula: } 1 \\
\text { Intra-abdominal abscess: } 2\end{array}$ & $\begin{array}{c}\text { Intestinal fistula: } 1 \\
\text { Intra-abdominal abscess: } 0\end{array}$ \\
\hline \multicolumn{2}{|c|}{1} & 0 \\
\hline
\end{tabular}

and more studies are necessary to confirm the results.

\section{Conclusion}

The results obtained by combining the intra-abdominal instillation therapy with suction seem to be promising, regarding the rate of abdominal closure, reducing the time to primary fascial closure and consequently in fewer complications associated with open abdomen, but prospective randomized studies are needed.

\section{References}

[1]. Moore-Olufemi SD, Xue H, Allen SJ, Moore FA, Stewart RH, et al., (2005) Effects of primary and secondary intra-abdominal hypertension on mesenteric lymph flow: implications for the abdominal compartment syndrome. Shock. 23(6): 571-575.

[2]. Amin AI, Shaikh IA (2009) Topical negative pressure in managing severe peritonitis: a positive contribution? World J Gastroenterol. 15(27): 33943397.

[3]. Emr B, Sadowsky D, Azhar N, Gatto LA, An G, et al., (2014) Removal of inflammatory ascites is associated with dynamic modification of local and systemic inflammation along with prevention of acute lung injury: in vivo and in silico studies. Shock. 41(4): 317-23.

[4]. Bernard GR, Artigas A, Brigham KL, Carlet J, Falke K, et al., (1994) Report of the American-European Consensus conference on acute respiratory distress syndrome: definitions, mechanisms, relevant outcomes, and clinical trial coordination. Consensus Committee. J Crit Care. 9(1): 72-81.

[5]. Scachtrupp A, Wauters J, Wilmer A (2007) What is the best animal model for ACS. Acta Clin Belg. 1: 225-232.

[6]. Lucas S (2007) The autopsy pathology of sepsis-related deat. Current Diagnostic Pathology. 13: 375-388.

[7]. Pugin J, Ricou B, Steinberg KP, Suter PM, Martin TR (1996) Proinflam- matory activity in bronchoalveolar lavage fluids from patients with ARDS, a prominent role for interleukin-1. Am J RespirCrit Care Med. 153(1): 1850-1856.

[8]. Kubiak BD, Albert SP, Gatto LA, Vieau CJ, Roy SK, et al., (2011) A clinically applicable porcine model of septic and ischemia/reperfusion-induced shock and multiple organ injury. J Surg Res. 166(1): e59-69.

[9]. Tao Q, Ren J, Ji Z, Liu S, Wang B, et al., (2014) VAWCM-Instillation Improves Delayed Primary Fascial Closure of Open Septic Abdomen. Gastroenterol Res Pract. 2014: 245182.

[10]. M D'Hondt, A D'Haeninck, L Dedrye, F Penninckx, R Aerts (2011) Can vacuum-assisted closure and instillation therapy (VAC-Instill ${ }^{\circ}$ therapy) play a role in the treatment of the infected open abdomen? Techniques in coloproctology. 15(1): 75-77.

[11]. Nunes VR, Barbuto RC, Vidigal PV, Pena GN, Rocha SL, et al., (2014) Effect of peritoneal cavity lavage with $0.9 \%$ and $3.0 \%$ saline solution in the lung and spleen of gerbils with induced peritonitis. Surg Infect (Larchmt). 15(2): 84-89.

[12]. Barrera Melgarejo E, Rodríguez Castro M, Borda Luque G, Najar Trujillo N (2010) Predictive mortality value of the peritonitis index of Mannheim. Rev Gastroenterol Peru. 30(3): 211-5.

[13]. Gabriel A, Shores J, Heinrich C, Bagai W, Kalina S, et al., (2008) Negative pressure wound therapy with instillation: a pilot study describing a new method for treating infected wounds. Int Wound J. 5(3): 399-413.

Special Issue on

"Trauma and Surgical Critical Care"

Edited by:

Kent Choi, University of Iowa Hospitals, USA E-mail: kent-choi@uiowa.edu 